\title{
ANALISIS RISIKO K3 PEMBERANTASAN HAMA PEKERJAAN PERTANIAN JERUK DI KABUPATEN BANYUWANGI
}

Fajar Khaula Rizkya Akbar' ${ }^{1}$, Mulyono ${ }^{2}$

${ }^{1,2}$ Departemen Kesehatan dan Keselamatan Kerja, Fakultas Kesehatan Masyarakat, Universitas Airlangga

Fajar.khaula.r.a-2014@fkm.unair.ac.id

\begin{abstract}
The many opportunities that exist in the agricultural sector, of course, there will be a lot of labor needed, the more workers and the more complex methods or technologies used will increase the risk of work-related illnesses or work-related accidents. The purpose of this study was to analyze the risk of $\mathrm{K} 3$ in citrus farmers in Sidorejo village, Purwoharjo sub-district, Banyuwangi district. This research is a descriptive study that uses a qualitative method with an observational approach referring to the AS / NZS 4360: 2004 standard for risk analysis on the work of citrus farmers in Sidorejo village, Banyuwangi district. Research instruments to assess the type of risk of work using the AS / NZS 4360: 2004 standard. The results showed that the risk of OHS found in the work of citrus farmers, especially at the stage of eradicating pests, is the risk of breathing pesticide fog (risk rating 6 is acceptable), the eyes are exposed to the mist of pesticides (risk rating 6 is acceptable), skin exposed to the mist of pesticides (risk rating 6 is acceptable), slip (risk rating 1 is acceptable) and too long to bring the load tanks on the shoulders (risk rating 5 is acceptable). The conclusion of this study is that the highest risk of OHS experienced by farmers is in the process of eradicating pests, especially when spraying pesticides. Exposure to pesticides can be through the eyes, breathing and skin.
\end{abstract}

Keywords: Health and Safety Risk Assesment, Orange Farmer, Sidorejo, Banyuwangi

\begin{abstract}
ABSTRAK
Banyaknya peluang yang ada di sektor pertanian tentu saja akan ada banyak tenaga kerja yang dibutuhkan, semakin banyak pekerja dan semakin kompleks metode atau teknologi yang digunakan akan meningkatkan resiko terjadinya penyakit akibat kerja atau kecelakaan akibat kerja. Tujuan dari penelitian ini adalah menganilisis risiko K3 di petani jeruk desa Sidorejo kecamatan Purwoharjo kabupaten Banyuwangi. Penelitian ini adalah penelitian deskriptif yang menggunakan metode kualitatif dengan pendekatan observasional mengacu pada standar AS/NZS 4360:2004. Instrumen penelitian untuk menilai jenis risiko pekerjaannya menggunakan standar AS/NZS 4360:2004, kemudian untuk mengidentifikasi bahaya pada setiap tahapan pekerjaan menggunakan metode JSA dan guna mengumpulkan informasi dari pekerja menggunakan metode in-depth interview. Hasil penelitian menunjukkan bahwa risiko K3 yang terdapat pada pekerjaan petani jeruk khususnya pada tahap pemberantasan hama adalah risiko menghirup kabut pestisida (risk rating 6 yaitu acceptable), mata terpapar kabut pestisida (risk rating 6 yaitu acceptable), kulit terpapar kabut pestisida (risk rating 6 yaitu acceptable), terpeleset (risk rating 1 yaitu acceptable) dan terlalu lama membawa beban tangki di pundak (risk rating 5 yaitu acceptable). Kesimpulan dari penelitian ini adalah risiko K3 paling tinggi yang dialami oleh petani terdapat pada proses pemberantasan hama, khususnya pada saat menyemprotkan pestisida. Paparan pestisida dapat melalui mata, pernafasan, dan kulit.
\end{abstract}

Kata Kunci: Analisis Risiko K3, Petani Jeruk, Sidorejo, Banyuwangi 


\section{PENDAHULUAN}

Bidang pertanian telah menjadi salah satu pekerjaan sektor informal yang banyak dilakukan oleh masyarakat di Indonesia. Pada setiap pekerjaan dan tempat bekerja selalu memiliki risiko dan bahaya (hazard) yang dapat mengancam keselamatan tenaga kerjanya. Risiko dan bahaya (hazard) tersebut dapat terjadi kapan saja, dimana saja dan menimpa siapa saja baik pada sektor formal maupun informal. Menurut data (International Labour Organization, 2013) menyebutkan bahwa 1 pekerja di dunia meninggal setiap 15 detik karena kecelakaan kerja dan 160 pekerja mengalami sakit akibat kerja. Pada bulan Mei 2013 diperkirakan sekitar 53,6\% kecelakaan kerja atau penyakit akibat kerja terjadi pada sektor pekerjaan informal dan $46,4 \%$ dari sektor pekerjaan formal. Di Indonesia terdapat petani yang mengalami gejala dan diagnosis ISPA sebesar 24.4\% (Badan Penelitian dan Pengembangan Kesehatan, 2013)

Seperti pupuk kimia yang digunakan selama proses pengolahan lahan juga dapat berpotensi mengakibatkan iritasi pada kulit, mata atau mengakibatkan gangguan kesehatan lainnya. Selain itu, pertanian masih dilakukan dengan menggunakan peralatan tradisional seperti cangkul, penyemprot manual dan keranjang angkut manual. Sehingga, terdapat beragam risiko yang memungkinkan untuk dialami oleh para petani jeruk, mulai dari risiko kecelakaan dari peralatan bertani, kondisi lingkungan di sekitar lahan pertanian, beban kerja sampai ergonomi.

Definisi risiko (risk) menurut ISO 45001:2016 merupakan kombinasi dari kemungkinan terjadinya peristiwa yang berhubungan dengan cidera parah atau sakit akibat kerja atau terpaparnya seseorang atau alat pada suatu bahaya. Pendapat lain menurut OHSAS 18001:2007, risiko adalah kombinasi dari kemungkinan (likelihood) terjadinya suatu peristiwa yang dapat membahayakan atau suatu paparan dengan konsekuensi (consequency) dari cidera yang timbul atau kesakitan yang disebabkan oleh paparan atau kejadian tersebut.

Sedangkan menurut Australian Standard/New Zealand Standard (2004), risiko adalah peluang muncul atau terjadinya sesuatu yang dapat menimbulkan dampak atau efek terhadap suatu objek. Risiko dapat diukur berdasarkan nilai likelihood (kemungkinan munculnya kejadian) dengan consequency (dampak yang timbul dari kejadian tersebut).
Risiko sendiri dapat dinilai secara kualitatif, semi-kuantitatif ataupun kuantitatif.

Job Safety Analysis (JSA) merupakan teknik yang digunakan untuk mengidentifikasi bahaya dan risiko pada setiap bagian pekerjaan, identifikasi dilakukan pada pekerjaan yang memiliki risiko tinggi, sehingga nantinya hasil identifikasi dapat dijadikan dasar dalam menentukan langkah pengendalian. JSA dilakukan pada saat awal pekerjaan akan dimulai, tujuannya tentu saja untuk mencegah terjadinya kecelakaan akibat risiko tinggi. Adanya penggunaan analisis JSA akan memudahkan pekerja untuk mengetahui potensi risiko di setiap tahap pekerjaan. Sehingga, akan meningkatkan awareness dan kesadaran akan pentingnya penerapan budaya $\mathrm{K} 3$ di lingkungan kerja.

\section{METODE}

Penelitian ini berdasarkan sifat analisis datanya adalah penelitian deskriptif yang menggunakan metode kualitatif dikarenakan penelitian ini menggambarkan tentang analisis risiko pada pekerjaan petani jeruk di desa Sidorejo Kabupaten Banyuwangi. Penelitian ini dilakukan dengan pendekatan observasional yang mengacu pada standar manajemen risiko AS/NZS 4360:2004.

Metode penelitian yang digunakan adalah metode deskriptif, dimana metode deskriptif adalah suatu fenomena yang terjadi di dalam masyarakat yang dideskripsikan atau digambarkan (Notoatmodjo, 2010). Populasi yang digunakan dalam penelitian adalah petani jeruk di desa Sidorejo kecamatan Purwoharjo, kabupaten Banyuwangi sebanyak 300 orang. Sampel pada penelitian adalah petani jeruk yang ada di Dusun Krajan, baik petani yang berjenis kelamin laki-laki maupun perempuan. Kriteria utama yang ditetapkan adalah subjek tersebut merupakan pemilik lahan, kemudian dilanjutkan dengan kriteria antara lain, berjenis kelamin laki-laki, berprofesi sebagai petani jeruk, dan berdomisili di Dusun Krajan Desa Sidorejo Kabupaten Banyuwangi. Penggunaan metode tersebut yang disesuaikan dengan kriteria menghasilkan sampel sebanyak 30 orang lakilaki.

Pada penelitian ini variabel yang diteliti merupakan variabel yang terdapat pada standar manajemen risiko. Komponen yang diambil dalam penelitian ini ada 3 (tiga), yaitu identifikasi risiko, penilaian risiko dan evaluasi risiko. 
Data didapatkan melalui metode wawancara, penelitian ini dimulai dengan melakukan obesrvasi lapangan guna mengidentifikasi segala potensi risiko dan bahaya yang ada di tempat kerja petani jeruk. Instrumen penelitian menggunakan metode JSA (Job Safety Analysis) digunakan untuk mengidentifikasi risiko pada tahap pemanenan, analisis risiko, penilaian risiko, dan evaluasi. Kemudian untuk mengumpulkan informasi dari responden atau pekerja menggunakan metode in-depth interview. Setelah itu dilanjutkan dengan melakukan identifikasi risiko dan analisis bahaya $\mathrm{K} 3$ yang terjadi di pekerjaan petani jeruk dan tempat kerjanya. Identifikasi risiko dan analisis bahaya tersebut dilakukan untuk menentukan nilai dari suatu potensi risiko dan bahaya. Penilaian tersebut dilakukan dengan menentukan nilai keparahan konsekuensi (consecuency), kemungkinan terjadi (likelihood) dan tingkat paparannya (exposure). Setalah menentukan ketiga nilai tersebut dilanjutkan ke tahap evaluasi risiko, selama proses analisis dengan kriteria risiko yang telah ditentukan.

Pada tahap evaluasi risiko dilakukan perhitungan Risk Score untuk menentukan risiko mana yang dapat diterima, dikendalikan dan diprioritaskan pengendaliannya, serta membandingkan nilai risiko yang telah ditemukan.
HASIL

Jumlah keseluruhan responden yang diwawancarai pada penelitian ini sebanyak 30 orang. Responden dalam penelitian ini memiliki kesamaan pada jenis kelamin (hanya laki, jenis pekerjaan dan kepemilikan. Sedangkan yang menjadi pembeda hanya usia dan pendidikan terakhir saja, seperti berikut. Jenis kelamin responden yang terlibat dalam penelitian ini hanya berasalah dari satu kelompok jenis kelamin. Dari responden yang diwawancarai seluruhnya berjenis kelamin laki-laki. Berdasarkan data primer hasil wawancara yang didapat semua responden memiliki jenis pekerjaan yang sama yaitu sebagai petani jeruk.

Responden dalam penelitian ini merupakan orang-orang yang memiliki pekerjaan dan jenis kelamin sama, yaitu lakilaki yang berprofesi sebagai petani jeruk. Berdasarkan tabel tersebut usia responden yang merupakan seorang petani jeruk pada penelitian ini didominasi oleh orang-orang yang berusia 50 tahun ke atas yakni sebesar $60 \%$ dari jumlah seluruh responden yang terlibat. Tingkat pendidikan terakhir seorang responden dapat menunjukkan pengetahuan dan daya pikir yang dimiliki oleh responden tersebut. Oleh karena itu dalam penelitian ini tingkat pendidikan responden dibagi menjadi empat bagian, yaitu SD, SMP, SMA dan Sarjana.

Tabel 1. Identifikasi Risiko Tahap Pemberantas Hama

\begin{tabular}{|l|l|l|l|l|l|}
\hline No & Potensi Cedera (What) & $\begin{array}{l}\text { Pekerja yang } \\
\text { Terpapar (Who) }\end{array}$ & $\begin{array}{c}\text { Lokasi } \\
\text { (Where) }\end{array}$ & $\begin{array}{c}\text { Waktu } \\
\text { (When) }\end{array}$ & $\begin{array}{l}\text { Penyebab Terjadi } \\
\text { (Why) }\end{array}$ \\
\hline 1. & $\begin{array}{l}\text { Menghirup kabut saat } \\
\text { menyemprotkan } \\
\text { Pestisida }\end{array}$ & $\begin{array}{l}\text { Petani } \\
\text { Jeruk } \\
(9 \text { orang) }\end{array}$ & $\begin{array}{l}\text { Lahan } \\
\text { pertanian } \\
\text { jeruk }\end{array}$ & $\begin{array}{l}15-20 \\
\text { hari } \\
\text { sekali }\end{array}$ & $\begin{array}{l}\text { Kelalaian pekerja, } \\
\text { frekuensi terpapar } \\
\text { risiko } \\
\text { yang tinggi }\end{array}$ \\
\hline 2. & $\begin{array}{l}\text { Mata terkena kabut } \\
\text { pestisida }\end{array}$ & $\begin{array}{l}\text { Petani } \\
\text { Jeruk } \\
(3 \text { orang })\end{array}$ & $\begin{array}{l}\text { Lahan } \\
\text { pertanian } \\
\text { jeruk }\end{array}$ & $\begin{array}{l}15-20 \\
\text { hari } \\
\text { sekali }\end{array}$ & $\begin{array}{l}\text { Kelalaian pekerja, } \\
\text { frekuensi terpapar } \\
\text { risiko } \\
\text { yang tinggi }\end{array}$ \\
\hline 3. & Kulit terpapar kabut & $\begin{array}{l}\text { Petani Jeruk } \\
(3 \text { orang) }\end{array}$ & $\begin{array}{l}\text { Lahan } \\
\text { pertanian } \\
\text { Jeruk }\end{array}$ & $\begin{array}{l}15-20 \text { hari } \\
\text { sekali }\end{array}$ & $\begin{array}{l}\text { Kelalaian pekerja, } \\
\text { frekuensi terpapar } \\
\text { risiko } \\
\text { yang tinggi }\end{array}$ \\
\hline 4. & Terpapar pestisida & $\begin{array}{l}\text { Petani } \\
\text { Jeruk } \\
(2 \text { orang })\end{array}$ & $\begin{array}{l}\text { Lahan } \\
\text { pertanian } \\
\text { jeruk }\end{array}$ & $\begin{array}{l}15-20 \text { hari } \\
\text { sekali }\end{array}$ & Kelalaian pekerja \\
\hline
\end{tabular}


Lanjutan

Tabel 1. Identifikasi Risiko Tahap Pemberantasan Hama

\begin{tabular}{|c|l|l|l|l|l|}
\hline No & $\begin{array}{c}\text { Potensi Cedera } \\
\text { (What) }\end{array}$ & \multicolumn{1}{|c|}{$\begin{array}{c}\text { Pekerja yang } \\
\text { Terpapar (Who) }\end{array}$} & $\begin{array}{l}\text { Lokasi } \\
\text { (Where) }\end{array}$ & $\begin{array}{c}\text { Waktu } \\
\text { (When) }\end{array}$ & \multicolumn{1}{c|}{$\begin{array}{c}\text { Penyebab } \\
\text { Terjadi (Why) }\end{array}$} \\
\hline $\begin{array}{l}\text { 5. } \\
\text { Menghirup kabut } \\
\text { saat } \\
\text { menyemprotkan } \\
\text { Pestisida }\end{array}$ & $\begin{array}{l}\text { Petani } \\
\text { Jeruk } \\
\text { (9 orang) }\end{array}$ & $\begin{array}{l}\text { Lahan } \\
\text { pertanian } \\
\text { jeruk }\end{array}$ & $\begin{array}{l}15-20 \\
\text { hari } \\
\text { sekali }\end{array}$ & $\begin{array}{l}\text { Kelalaian pekerja, frekuensi } \\
\text { terpapar risiko } \\
\text { yang tinggi }\end{array}$ \\
\hline 6. & $\begin{array}{l}\text { Mata terkena } \\
\text { kabut pestisida }\end{array}$ & $\begin{array}{l}\text { Petani } \\
\text { Jeruk } \\
\text { (3 orang) }\end{array}$ & $\begin{array}{l}\text { Lahan } \\
\text { pertanian } \\
\text { jeruk }\end{array}$ & $\begin{array}{l}15-20 \\
\text { hari } \\
\text { sekali }\end{array}$ & $\begin{array}{l}\text { Kelalaian pekerja, frekuensi } \\
\text { terpapar risiko } \\
\text { yang tinggi }\end{array}$ \\
\hline
\end{tabular}

Salah satu risiko K3 yang dapat ditemui pada saat menyemprotkan pestisida menggunakan tangki sprayer adalah ketika pundak petani yang terlalu lama membawa beban tangki seperti yang dialami oleh 1 orang petani, sehingga menimbulkan rasa sakit pada pundak. Risiko K3 sangat sering terjadi pada fase pemberantasan hama ini, mulai dari risiko terpapar kabut pestisida bahkan risiko kesehatan dan keselamatan kerja K3 lainnya. Seperti pada saat penyemprotan pestisida, apabila petani tidak memperhatikan arah angin saat melakukan penyemprotan maka kabut pestisida dapat kembali ke petani dan menyerang bagian tubuh petani, seperti bagian pernafasan petani yang dialami oleh sebanyak 9 orang petani, kemudian bagian mata seperti yang dialami oleh 3 orang petani, dan kulit yang juga dialami oleh 3 orang petani. Risiko K3 tersebut dapat terjadi apabila setiap melakukan penyemprotan pestisida para petani tidak menggunakan APD (Alat Pelindung Diri) dan tidak memperhatikan arah angin.

Saat melakukan pekerjaan penyemprotan pestisida ini pun para petani harus waspada dengan risiko terpeleset seperti yang telah dialami oleh 2 orang petani dengan frekuensi kejadian yang sering. Risiko terpeleset ini dapat disebabkan karena tanah sawah yang basah dan petani yang tidak menggunakan APD (Alat Pelindung Diri) untuk mencegah terjadinya risiko terpeleset.

Tabel 2. Hasil analisis risiko menggunakan metode JSA

\begin{tabular}{|c|c|c|c|c|c|c|}
\hline \multirow{2}{*}{\multicolumn{7}{|c|}{$\begin{array}{l}\text { Pekerjaan : Petani Jeruk } \\
\text { Langkah Kerja : Pemberantasan Hama }\end{array}$}} \\
\hline & & & & & & \\
\hline \multirow[t]{2}{*}{$\begin{array}{l}\text { Potensi } \\
\text { Cedera } \\
\end{array}$} & Konsekuensi & \multicolumn{4}{|c|}{ Risk Matrix } & Pengendalian yang ada \\
\hline & & Severity & Likelihood & Eksposure & $\begin{array}{l}\text { Risk } \\
\text { Rating }\end{array}$ & \\
\hline $\begin{array}{l}\text { 1. Menghirup } \\
\text { kabut } \\
\text { pestisida }\end{array}$ & $\begin{array}{l}\text { 1. Pusing, } \\
\text { mual, } \\
\text { kesadaran } \\
\text { menurun, } \\
\text { keracunan }\end{array}$ & 0.5 & 6 & 2 & 6 & $\begin{array}{l}\text { APD : menggunakan } \\
\text { masker penutup hidung } \\
\text { yang terbuat dari kain } \\
\text { kaos }\end{array}$ \\
\hline $\begin{array}{l}\text { 2. Mata } \\
\text { terkena } \\
\text { kabut } \\
\text { pestisida }\end{array}$ & $\begin{array}{l}\text { 2. Perih, } \\
\text { iritasi, berair }\end{array}$ & 0.5 & 6 & 2 & 6 & $\begin{array}{l}\text { APD : Menggunakan } \\
\text { kacamata regular }\end{array}$ \\
\hline
\end{tabular}




\section{Lanjutan}

Tabel 2. Hasil analisis risiko menggunakan metode JSA

\begin{tabular}{|c|c|c|c|c|c|c|}
\hline \multirow{2}{*}{\multicolumn{7}{|c|}{$\begin{array}{l}\text { Pekerjaan : Petani Jeruk } \\
\text { Langkah Kerja : Pemberantasan Hama }\end{array}$}} \\
\hline & & & & & & \\
\hline \begin{tabular}{|l|} 
3. Kulit \\
terpapar \\
kabut \\
Pestisida
\end{tabular} & $\begin{array}{l}\text { 3. gatal, iritasi } \\
\text { kulit }\end{array}$ & 0.5 & 6 & 2 & 6 & $\begin{array}{l}\text { APD : Baju kaos lengan } \\
\text { panjang, celana panjang, } \\
\text { penutup kepala }\end{array}$ \\
\hline 4. Terpeleset & $\begin{array}{l}\text { 4. memar, } \\
\text { keseleo, sakit } \\
\text { pinggang }\end{array}$ & 0.5 & 6 & 2 & 6 & APD : Sepatu boot \\
\hline $\begin{array}{l}5 . \text { Terlalu } \\
\text { lama } \\
\text { membawa } \\
\text { beban tangki } \\
\text { di pundak }\end{array}$ & 5. Low back & 0.5 & 10 & 2 & 5 & \\
\hline $\begin{array}{ll} & \text { Risiko } \\
\text { yang paling } \\
\text { pemberantasan } \\
\text { melalui perna } \\
\text { tersebut memi }\end{array}$ & $\begin{array}{l}\text { kesehatan dan } \\
\text { tinggi terj. } \\
\text { n hama adalah } \\
\text { afasan, kulit, } \\
\text { iliki nilai risk }\end{array}$ & elam & & $\begin{array}{l}\text { yang } \\
\text { Sehing } \\
\text { intensi } \\
\text { tahap } \\
\text { terjadi }\end{array}$ & & $\begin{array}{l}\text { alam kategori acceptabl } \\
\text { nya tindakan penguranga } \\
\text { enyemprotan pestisida pa } \\
\text { in hama agar risiko dap } \\
\text { ninimal mungki }\end{array}$ \\
\hline
\end{tabular}

Tabel 3. Evaluasi Risiko Tahap Pemberantasan Hama

\begin{tabular}{|c|c|c|c|}
\hline No & $\begin{array}{l}\text { Tahapan } \\
\text { Pekerjaan }\end{array}$ & Hasil Penilaian Risiko (Risk Rating) & Tindakan yang perlu diambil \\
\hline 1. & $\begin{array}{l}\text { Menyemprotkan } \\
\text { pestisida } \\
\text { Menyemprotkan } \\
\text { pestisida }\end{array}$ & $\begin{array}{l}\text { Menghirup kabut saat menyemprotkan } \\
\text { pestisida dengan nilai } \mathbf{6} \text { (acceptable) } \\
\text { Mata terkena kabut pestisida dengan } \\
\text { nilai } \mathbf{6} \text { (acceptable) } \\
\text { - Kulit terpapar kabut pestisida dengan } \\
\text { nilai } \mathbf{6} \text { (acceptable) } \\
\text { - Terpeleset saat menyemprotkan } \\
\text { pestisida dengan nilai } \mathbf{6} \text { (acceptable) } \\
\text { - Terlalu lama membawa beban tangki } \\
\text { di pundak saat menyemprotkan pestisida } \\
\text { dengan nilai } \mathbf{5} \text { (acceptable) }\end{array}$ & $\begin{array}{l}\text { - Pengurangan intensitas } \\
\text { kegiatan } \\
\text { - Pengurangan intensitas } \\
\text { kegiatan } \\
\text { - Pengurangan intensitas } \\
\text { kegiatan } \\
\text { - Pengurangan intensitas } \\
\text { kegiatan }\end{array}$ \\
\hline
\end{tabular}


Risiko kesehatan dan keselamatan kerja yang terjadi pada tahap pemberantasan hama adalah menghirup kabut saat menyemprotkan pestisida dengan nilai 6 (acceptable), mata terkena kabut pestisida dengan nilai 6 (acceptable), kulit terpapar kabut pestisida dengan nilai 6 (acceptable), terpeleset saat menyemprotkan pestisida dengan nilai 6 (acceptable), dan terlalu lama membawa beban tangki di pundak saat menyemprotkan pestisida dengan nilai 5 (acceptable). Sehingga perlu adanya tindakan pengurangan intensitas kegiatan penyemprotan pestisida pada tahap pemberantasan hama agar risiko dapat terjadi seminimal mungkin.

\section{PEMBAHASAN}

Setiap pekerjaan memiliki risiko di bidang kesehatan dan keselamatan kerja, walaupun pertanian jeruk merupakan perkerjaan di sektor informal, namun pertanian jeruk tetap memiliki beberapa risiko. Risiko pada pekerjaan petani jeruk ini bervariasi pada setiap tahap pekerjaannya, mulai risiko rendah hingga risiko tinggi. Setiap tahapan pekerjaan petani jeruk dilakukan pada waktu yang berbeda dengan jangka waktu yang panjang. Guna menyiasati proses produksi jeruk yang lama, sebagian besar petani jeruk memiliki lebih dari 1 (satu) lokasi lahan pertanian, hal tersebut memungkinkan setiap lahannya memiliki tahapan pertanian yang berbeda. Tujuannya untuk menjamin kelangsungan panen dan pendapatan perekonomian petani jeruk. Maka penelitian ini dapat dilakukan pada setiap tahap pekerjaan petani jeruk. Penilaian yang telah dilakukan terhadap tahapan-tahapan kerja petani jeruk mulai pada tahapan persiapan lahan, pemupukan, pemberantasan hama, irigasi, penjarangan buah, pemangkasan cabang, dan penyiangan gulma. Penilaian tersebut telah mendapatkan hasil bahwa setiap tahapan pekerjaan tersebut memiliki bahaya dan risiko tinggi yang berbeda-beda

Para petani jeruk sudah melalukan upaya-upaya untuk mengendalikan bahaya dan risiko yang mungkin terjadi didalam pekerjaannya. Namun tetap saja masih ada risiko dan bahaya yang terjadi selama bekerja. Apabila telah terjadi kecelakaan saat melakukan pekerjaan petani jeruk maka akan menimbulkan kerugian dari segi kesehatan dan finansial bagi para petani.
Sebagian besar petani jeruk merasa tidak terdapat dampak ketika menyemprotkan pestisida, pada penelitian (Yuantari, Widianarko dan Sunoko, 2015) perasaan tidak merasakan pajanan pestisida pada tubuh petani akan berbahaya bila berlangsung terus menerus, karena keracunan kronis banyak yang dialami oleh petani. (Jintana et al., 2009) menyatakan pekerja yang terpajan pestisida kadar kolinesterasenya menurun dibandingkan kontrol. Bila pekerja tidak menyadari akan pajanan dalam tubuhnya dapat menyebabkan meningkatnya kejadian keracunan kronis pada pestisida oleh petani.

Menurut (Yuantari, Widianarko dan Sunoko, 2015) terdapat risiko terpajan pestisida pada petani melalui inflasi, hal ini terjadi karena setiap kali menghirup udara di lahan pertanian tanpa disadari petani menghirup pestisida. Selain itu pajanan pestisida dapat melalui dermal ketika petani berinteraksi langsung dengan pestisida tersebut ketika proses penyemprotan pestisida, khususnya pada area punggung yang disebabkan oleh resapan pestisida dari tangki semprot yang dipanggul oleh petani.

Dampak paparan pestisida tersebut banyak menumpuk terhadap kulit petani dapat mengakibatkan iritasi dan gatal - gatal. Risiko yang paling tinggi pada tahap pemberantasan hama adalah terpapar pestisida melalui saluran pernafasan, kemudian mata, dan kulit. Dampaknya juga dapat dirasakan secara langsung oleh petani saat terpapar melalui pernafasan, kulit, ataupun mata. Lambung dan usus yang terpapar pestisida akan menunjukkan respon mulai dari yang sederhana seperti iritasi, rasa panas, mual. muntah hingga respon fatal yang dapat menyebabkan kematian seperti perforasi, pendarahan dan korosi lambung. Muntah muntah, sakit perut dan diare adalah gejala umum dari keracunan pestisida (Pamungkas, 2016).

Tahapan pekerjaan pemberantasan hama memiliki risiko paling tinggi dari semua tahapan pekerjaan petani jeruk, karena pada tahapan ini petani jeruk secara langsung terpapar racun pestisida beberapa kali. Dampak dari keracunan pestisida dapat menimbulkan gejala muntah, diare, dyspnea, penglihatan kabur, paresthesia, bicara cadel, dan nyeri dada (Kim et al., 2013). Risiko paling tinggi pada paparan pestisida dapat mengakibatkan dampak seperti mual dan keracunan yang 
langsung terasa oleh petani. Sama halnya apabila petani terkena paparan pestisida di mata, maka mata akan terasa perih dan iritasi. Pada penelitian yang dilakukan (Pamungkas, 2016) disebutkan efek akut lokal jika hanya mempengaruhi bagian tubuh yang terkena kontak langsung dengan pestisida biasanya bersifat iritasi mata, hidung, tenggorokan dan kulit. Risiko-risiko tersebut dapat dialami oleh para petani jeruk apabila tidak mematuhi UU No. 1 Tahun 1970 tentang Keselamatan Kerja, yaitu mengenai penggunaan APD (Alat Pelindung Diri) saat memasuki tempat kerja (Departemen Hukum dan PerundangUndangan, 1970).

Kemudian risiko selanjutnya yang mungkin terjadi adalah terpeleset, frekuensi terjadinya terpeleset sering dialami oleh para petani. Pada saat penyemprotan ini juga para petani dapat mengalami risiko ergonomi yang menyebabkan low back pain, akibat terlalu lama mengangkut atau menggendong tangki sprayer. Menurut (Tualeka, 2013) terdapat bahaya ergonomi saat menyemprotkan pestisida yaitu beban tangki gendong yang berlebihan. Risiko ini dapat dialami oleh petani jeruk apabila tidak memperhatikan kondisi lokal spesifik tempat bekerja seperti yang tercantum pada PP No. 81 Tahun 2001 tentang Alat dan Mesin Budidaya Tanaman (Kementerian Kesehatan Republik Indonesia, 2001)

\section{KESIMPULAN}

Pada tahap pemberantasan hama terdapat beberapa risiko $\mathrm{K} 3$, antara lain risiko terhirupnya kabut pestisida sehingga menyebabkan keracunan, terpaparnya mata dan kulit oleh kabut pestisida yang mengakibatkan iritasi, terpeleset yang dapat menyebabkan memar dan terkilir serta risiko mengalami low back pain dikarenakan terlalu lama membawa beban tangki di pundak.

\section{DAFTAR PUSTAKA}

Australian Standard/New Zealand Standard. 2004. Australian Standard/New Zealand Standard Risk Management 4360:2004. Sydney and Wellington: Author.

Badan Penelitian dan Pengembangan Kesehatan. 2013. Riset Kesehatan Dasar (RISKESDAS) 2013, Laporan Nasional 2013. doi: 1 Desember 2013.
Departemen Hukum dan PerundangUndangan. 1970. Undang-Undang Nomor 1 Tahun 1970 Tentang Keselamatan Kerja.

International Labour Organization. 2013. Keselamatan dan Kesehatan Kerja di Tempat Kerja. Diakses dari: http://www.ilo.org/wcmsp5/groups/pu blic\%0A/---asia/--ro-bangkok/---ilojakarta/documents/publication/wcms_5 48 900.pdf\%0A.

Jintana, S. et al. 2009. Cholinesterase activity, pesticide exposure and health impact in a population exposed to organophosphates, International Archives of Occupational and Environmental Health, 82(7), pp. 83342. doi: 10.1007/s00420-009-0422-9.

Kementerian Kesehatan Republik Indonesia. 2001. Peraturan Pemerintah Republik Indonesia Nomor 81 Tahun 2001 tentang Alat dan Mesin Budidaya Tanaman.

Kim, J. H. et al. 2013. Work-related risk factors by severity for acute pesticide poisoning among male farmers in South Korea, International journal of environmental research and public health, (1100-1112). doi: 10.3390/ijerph10031100.

Notoatmodjo, S. 2010. Health Research Methodology. Jakarta: Rineka Cipta.

Pamungkas, O. S. 2016. Bahaya Paparan Pestisida terhadap Kesehatan Manusia, Bioedukasi, 14(1), pp. 27-31. Diakses darihttps://jurnal.unej.ac.id/index.php/ BIOED/article/view/4532

Tualeka, E. D. dan A. R. 2013. Risk Assesment dan Pengendalian Risiko pada Sektor Pertanian (Studi Kasus di Pertanian Bawang Merah Desa Kendalrejo, Kecamatan Bagor, Kabupaten Nganjuk), The Indonesian Journal of Occupational Safety and Health, 2(2), pp. 154 - 161. Diakses dari http://repository.unair.ac.id/23142/

Yuantari, M. G. C., Widianarko, B. dan Sunoko, H. R. 2015. Analisis Risiko Pajanan Pestisida Terhadap Kesehatan Petani, Jurnal Kesehatan Masyarakat, 10(2), pp. 239 - 245. doi: 10.15294/kemas.v10i2.3387. 